\title{
Total haemoglobin mass, blood volume and morphological indices among athletes from different sport disciplines
}

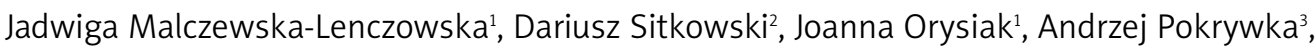 \\ Zbigniew Szygula ${ }^{4,5}$
}

\author{
1Department of Nutrition Physiology, Institute of Sport, Warsaw, Poland \\ 2Department of Physiology, Institute of Sport, Warsaw, Poland \\ 3Department of Anti-Doping Research, Institute of Sport, Warsaw, Poland \\ ${ }^{4}$ Department of Sports Medicine, University School of Physical Education, Cracow, \\ Poland \\ ${ }^{5}$ University of Social Sciences, Lodz, Poland \\ Submitted: 20 February 2013 \\ Accepted: 20 February 2013
}

Arch Med Sci 2013; 9, 5: 780-787

DOI: 10.5114/aoms.2013.36926

Copyright @ 2013 Termedia \& Banach

\author{
Corresponding author: \\ Jadwiga \\ Malczewska-Lenczowska \\ Institute of Sport \\ 2/16 Trylogii St \\ 01-982 Warsaw, Poland \\ Phone: +48228340812 \\ Fax: +48228350904 \\ E-mail: jadwiga.malczewska@ \\ insp.waw.pl
}

\begin{abstract}
Introduction: Haemoglobin is a key determinant of maximal oxygen uptake. This study's objective was to assess total haemoglobin mass (tHb-mass), as well as blood volume and morphological indices in athletes training different sports disciplines.

Material and methods: This study was conducted on 176 endurance and nonendurance athletes (males and females). tHb-mass, blood volume (BV), plasma volume (PV), and red cell volume (RCV) were determined by optimized carbon monoxide rebreathing method. Haemoglobin concentration $(\mathrm{Hb})$, haematocrit $(\mathrm{Hct})$, red blood count (RBC) were also determined.

Results: In endurance sports, gender regardless, no significant differences in relative mean values of tHb-mass $(12.8-13.1 \mathrm{~g} / \mathrm{kg}$ - males; $10.4-10.6 \mathrm{~g} / \mathrm{kg}$ females), BV (90.8-94.0 ml/kg - males; 82.7-86.9 ml/kg - females), RCV (36.6$38.0 \mathrm{ml} / \mathrm{kg}$ - males; $31.1-31.5 \mathrm{ml} / \mathrm{kg}$ - females) or of PV in males $(54.2-56.4 \mathrm{ml} / \mathrm{kg}$ ) were observed. The above indices' relative values, gender regardless, were significantly lower in judo $(11.2 \pm 0.7 \mathrm{~g} / \mathrm{kg}, 81.8 \pm 5.9 \mathrm{ml} / \mathrm{kg}, 48.6 \pm 4.5 \mathrm{ml} / \mathrm{kg}$ and 33.1 $\pm 2.0 \mathrm{ml} / \mathrm{kg}$ - males; $9.3 \pm 0.7 \mathrm{~g} / \mathrm{kg}, 74.3 \pm 5.6 \mathrm{ml} / \mathrm{kg}, 46.4 \pm 4.0 \mathrm{ml} / \mathrm{kg}$ and 27.9 $\pm 2.1 \mathrm{ml} / \mathrm{kg}$ - females) compared to endurance sports ( $p<0.001)$. No substantial differences were observed in morphological blood indices in males, whereas this differentiation was found between certain sports in female athletes. Conclusions: The lack of differences in tHb-mass, BV, PV and RCV in endurance sports and presence of this differentiation between various sports shows that the types of training might affect levels of mentioned indices. Measurements of $\mathrm{tHb}$-mass and BV parameters prove $\mathrm{Hb}$, Hct and RBC to have limited value for haematological status evaluations.
\end{abstract}

Key words: total haemoglobin mass, blood volume indices, blood morphology, athletes.

\section{Introduction}

Among a number of factors that affect aerobic capacity, two are of fundamental importance: oxygen transport to skeletal muscles via the cardiovascular system and oxygen consumption [1]. Those factors are often 
implemented as indices in an assessment of physical performance in athletes [2]. On the other hand, efficient oxygen transport to tissues is further determined by heart size, amount of haemoglobin in the blood circulation system and blood volume (BV) $[1,3,4]$. For this reason, a high level of total haemoglobin mass (tHb-mass) and high BV are necessary to reach high aerobic capacity $[4,5]$. An increase in $\mathrm{tHb}$-mass by $1 \mathrm{~g}$ causes a rise in $\mathrm{VO}_{2}$ max by ca. $4 \mathrm{ml} / \mathrm{min}$ [6], whereas higher BV, through the increase in PV and/or increase in erythrocyte mass, leads to an increase in stroke volume and cardiac output, which also results in higher $\mathrm{VO}_{2} \max$ (a difference in $\mathrm{BV}$ of $1.0 \mathrm{ml}$ causes a change in $\mathrm{VO}_{2} \mathrm{max}$ by $0.7 \mathrm{ml} / \mathrm{g} \cdot \mathrm{min}$ ) [7]. The close relationship between aerobic capacity indices, tHb-mass and/or BV is confirmed by the results of numerous studies [3, 8-11]. However, such dependency is not observed for blood haemoglobin concentration [12-15]. Despite of that, haemoglobin concentration together with other biochemical indices expressed as concentration is commonly used in sports diagnostics [16-18].

The results of the studies show that tHb-mass in endurance athletes is considerably higher than in untrained subjects or people with a low level of fitness. The level of this index in elite endurance athletes calculated per body mass might be even by $40-50 \%$ higher than in the untrained $[7,11]$. The results also indicated that $\mathrm{tHb}$-mass varied in different elite endurance athletes, which might be caused by a number of factors, with particular focus on specificity of sport [10], level of fitness of the athletes [19], age [20], training load at the time of the measurement [21] and genetic factors [19]. This was confirmed in a study by Heinicke et al. [10] where $\mathrm{tHb}$-mass ranged from 13.2 in swimmers to $15.4 \mathrm{~g} / \mathrm{kg}$ body mass in professional cyclists.

The impact of exercise alone on increase in tHb-mass has not been so far precisely identified. It is generally accepted that regular training regimes of endurance character in sea level conditions cause both cardiac and haematological adaptations, with highly trained subjects exhibiting insignificant increases in $\mathrm{tHb}$-mass ranging from $2 \%$ to $4.4 \%$ [7, 21].

A review of the literature concerning the evaluation of tHb-mass as well as BV, PV and erythrocyte volume (RCV) in athletes reveals that a number of sport disciplines, even those of an endurance type, have not yet been characterized in terms of the above indices. Furthermore, few studies have compared these indices in endurance and non-endurance sports, which is a limiting factor in comparison of tHb-mass in athletes at a high level of fitness who perform exercise of different character.

Therefore, the aim of the study was to compare total haemoglobin mass, and volumes of blood, plasma, and erythrocyte mass in athletes training in different sport disciplines in relation to commonly used blood morphology indices.

\section{Material and methods}

\section{Subjects}

One hundred and seventy-six athletes (both male and female) from different endurance sports (i.e. cross-country skiing, middle and long distance running, modern pentathlon, and Nordic combined) and combat sports (judo) volunteered for the study. Most of the study participants were national elite athletes and members of national senior or junior teams. All the tested subjects were informed in detail about the risk inherent in participation in the study, which they confirmed with a signature in the presence of a witness. In the case of under-aged people, the consent was given by one of their legal guardians. Although all the subjects had current medical certificates that confirmed the lack of contraindications for practising competitive sports, the subjects were given a medical examination in order to exclude individuals who on the day of the study showed symptoms of infectious or cardiovascular diseases. The study was approved by the local Research Ethics Committee and conformed to the standards set by the Declaration of Helsinki.

\section{Study design}

The study consisted of three stages performed on one day in the following order: venous blood sampling, anthropometric measurements, evaluation of tHb-mass.

\section{Venous blood sampling and analysis}

The blood samples were withdrawn from the antecubital vein in the morning in the fasting state after staying at least $15 \mathrm{~min}$ in a sitting position. Haemoglobin concentration $(\mathrm{Hb})$, haematocrit ( $\mathrm{Hct}$ ), red blood count (RBC), and percentage of reticulocytes (Ret) were determined by using an ADVIA 120 haematological analyser (Siemens, Germany).

\section{Anthropometric measurements}

The anthropometric measurements encompassed body height and mass and thickness of four skinfolds (biceps, triceps, subscapular and suprailiac). They were taken by the same experienced researcher. Based on the obtained results, body composition (body fat and fat-free mass [FFM]) was evaluated [22].

\section{tHb-mass and blood volume indices}

A method based on carbon monoxide rebreathing was employed. A detailed description of this method was given in publications by its authors $[23,24]$. Briefly, in order to stabilize PV, the subjects remained in a sitting position for at least $15 \mathrm{~min}$ before the test and then they were connected to 




a spirometer (Blood tec, GbR, Germany) filled with 3-4 I of medical oxygen. After a maximum exhalation, the subjects were instructed to make a full inhalation, where they obtained a CO bolus in the amount of $1.0 \mathrm{ml} / \mathrm{kg}$ body mass (BM) for males and $0.8 \mathrm{ml} / \mathrm{kg} \mathrm{BM}$ for females in the case of endurance athletes and $0.8 \mathrm{ml} / \mathrm{kg}$ BM for males and $0.7 \mathrm{ml} / \mathrm{kg} B M$ for females in judoists, and then hold their breath at the peak inhalation for $10 \mathrm{~s}$. Immediately afterwards, the subjects respired naturally through the spirometer for 1 min $50 \mathrm{~s}$. Samples of the arterialized capillary blood (Finalgon ${ }^{\circledR}$, Boehringer Ingelheim, Germany) were taken from the earlobe three times: directly before the test and in the $6^{\text {th }}$ and $8^{\text {th }}$ min after the respiration through the spirometer was started. Measurements of the percentage value of carboxyhaemoglobin ( $\mathrm{HbCO} \%$ ) (ABL 80 Flex, Radiometer, Denmark) were performed in triplicate samples before the test and in the $8^{\text {th }} \mathrm{min}$, and in duplicate samples in the $6^{\text {th }}$ min of the study. The remaining $C O$ concentration in the lungs and the spirometer was measured by a portable carbon monoxide analyser (Dräger Pac ${ }^{\circledR 7000, ~ G e r-~}$ many). The same analyser was used to check whether any leak of CO was present during respiration through the spirometers. Special computer software (Blood Volume Measurement: SpiCO ${ }^{\circledR}$; Blood tec, Bayreuth, Germany) was employed to calculate tHb-mass and BV indices. The typical error (TE) in our laboratory with $9 \mathrm{du}$ plicated measures (1-5 days lag between the test), established 1 month before the present study, was $1.37 \%$.

\section{Statistical analysis}

All the data are presented as means and standard deviations, and were analysed using the Statistica 10 software package (StatSoft Inc., Tulsa, USA). Inter-group differences between the mean values separately for males and females were determined by one-way analysis of variance (ANOVA). If statistically significant differences were observed, a post-hoc Bonferroni analysis was performed. The statistical significance was set at $p<0.05$.

\section{Results}

\section{Characteristics of subjects}

The physical characteristics of subjects, separated by gender and sports, as well as 
basic data concerning sports experience and training load, are shown in Table I.

\section{Haemoglobin mass and blood, plasma and red cell volumes}

Mean relative values of $\mathrm{tHb}$-mass and volume parameters, normalized to total body mass, are presented in Table II. The mean values of tHb-mass calculated per kg body mass in the studied endurance sports were very similar and ranged from 10.4-10.6 $\mathrm{g} / \mathrm{kg} \mathrm{BM}$ in women to $12.8-13.1 \mathrm{~g} / \mathrm{kg}$ BM in men. This index was significantly higher in endurance sports compared to the representatives of judo, both in female (by $12-14 \%, p<0.001$ ) and male athletes (by $14-17 \%, p<0.001$ ). Mean values of BV and RCV calculated per kg body mass (like tHbmass) were similar in all endurance sports and significantly higher than in non-endurance sports, both in the groups of women and men. Mean values of PV were also significantly higher in both male and female endurance athletes compared to judokas of both genders, although significant differences were observed among female athletes of two endurance sports: the mean value of this parameter was significantly lower in female crosscountry skiers compared to female modern pentathlon athletes.

Table II. Total hemoglobin mass and volume parameters normalized to body mass (mean \pm SD)

\begin{tabular}{|c|c|c|c|c|c|}
\hline Variable & $N$ & $\begin{array}{l}\text { tHb-mass } \\
{[\mathrm{g} / \mathrm{kg} \mathrm{BM}]}\end{array}$ & $\begin{array}{c}\text { Blood volume } \\
{[\mathrm{ml} / \mathrm{kg} \mathrm{BM}]}\end{array}$ & $\begin{array}{c}\text { Plasma volume } \\
{[\mathrm{ml} / \mathrm{kg} \mathrm{BM}]}\end{array}$ & $\begin{array}{c}\text { Erythrocyte volume } \\
{[\mathrm{ml} / \mathrm{kg} \mathrm{BM}]}\end{array}$ \\
\hline \multicolumn{6}{|l|}{ Males } \\
\hline Cross-country skiing [1] & 20 & $13.1 \pm 0.8^{[2]}$ & $93.3 \pm 6.4[2]$ & $55.3 \pm 5.0[2]$ & $38.0 \pm 2.0[2]$ \\
\hline Judo [2] & 34 & $11.2 \pm 0.7[1,3,4,5]$ & $81.8 \pm 5.9[1,3,4,5]$ & $48.6 \pm 4.5[1,3,4,5]$ & $33.1 \pm 2.0[1,3,4,5]$ \\
\hline Middle- and long-distance running [3] & 21 & $13.1 \pm 1.0^{[2]}$ & $93.1 \pm 7.6[2]$ & $55.6 \pm 5.7^{[2]}$ & $37.5 \pm 2.5^{[2]}$ \\
\hline Modern pentathlon [4] & 24 & $12.8 \pm 0.7[2]$ & $94.0 \pm 5.8^{[2]}$ & $56.4 \pm 4.5[2]$ & $37.7 \pm 2.2^{[2]}$ \\
\hline Nordic combined [5] & 8 & $12.8 \pm 0.6[2]$ & $90.8 \pm 5.0^{[2]}$ & $54.2 \pm 4.4[2]$ & $36.6 \pm 2.2^{[2]}$ \\
\hline Total number & 107 & & & & \\
\hline \multicolumn{6}{|l|}{ Females } \\
\hline Cross-country skiing [1] & 20 & $10.6 \pm 1.1^{[2]}$ & $82.6 \pm 6.0[2]$ & $51.1 \pm 3.4[2,4]$ & $31.5 \pm 3.2^{[2]}$ \\
\hline Judo [2] & 16 & $9.3 \pm 0.7[1,3,4]$ & $74.3 \pm 5.6[1,3,4]$ & $46.4 \pm 4.0[1,3,4]$ & $27.9 \pm 2.1[1,3,4]$ \\
\hline Middle- and long-distance running [3] & 19 & $10.6 \pm 0.9[2]$ & $86.1 \pm 7.3^{[2]}$ & $54.8 \pm 5.5^{[2]}$ & $31.3 \pm 2.7^{[2]}$ \\
\hline Modern pentathlon [4] & 14 & $10.4 \pm 0.9[2]$ & $86.9 \pm 7.9[2]$ & $55.8 \pm 5.5^{[1,2]}$ & $31.1 \pm 2.7[2]$ \\
\hline Total number & 69 & & & & \\
\hline
\end{tabular}

tHb-mass - total hemoglobin mass. BM - body mass. [1, 2, 3, 4, 5] Significant differences within male or female groups

Table III. Total hemoglobin mass and volume parameters normalized to fat free mass (mean \pm SD)

\begin{tabular}{|c|c|c|c|c|c|}
\hline Variable & $N$ & $\begin{array}{l}\text { tHb-mass } \\
{[\mathrm{g} / \mathrm{kg} \mathrm{BM}]}\end{array}$ & $\begin{array}{l}\text { Blood volume } \\
\text { [ml/kg BM] }\end{array}$ & $\begin{array}{c}\text { Plasma volume } \\
\text { [ml/kg BM] }\end{array}$ & $\begin{array}{c}\text { Erythrocyte volume } \\
{[\mathrm{ml} / \mathrm{kg} \mathrm{BM}]}\end{array}$ \\
\hline \multicolumn{6}{|l|}{ Males } \\
\hline Cross-country skiing [1] & 20 & $14.6 \pm 1.0[2]$ & $103.7 \pm 7.2^{[2]}$ & $61.4 \pm 5.5^{[2]}$ & $42.2 \pm 2.4[2]$ \\
\hline Judo [2] & 34 & $12.9 \pm 0.9[1,3,4]$ & $94.1 \pm 6.4[1,3,4]$ & $55.9 \pm 4.5^{[1,3,4]}$ & $38.2 \pm 2.8^{[1,3,4]}$ \\
\hline Middle- and long-distance running [3] & 21 & $14.4 \pm 1.0[2]$ & $102.3 \pm 7.7[2]$ & $61.2 \pm 6.0^{[2]}$ & $41.2 \pm 2.6^{[2]}$ \\
\hline Modern pentathlon [4] & 24 & $14.2 \pm 0.9[2]$ & $104.9 \pm 6.9[2]$ & $62.9 \pm 5.0[2]$ & $42.1 \pm 2.7[2]$ \\
\hline Nordic combined [5] & 8 & $13.7 \pm 0.7$ & $97.1 \pm 4.4$ & $58.0 \pm 4.4$ & $39.1 \pm 2.0$ \\
\hline Total number & 107 & & & & \\
\hline \multicolumn{6}{|l|}{ Females } \\
\hline Cross-country skiing [1] & 20 & $13.6 \pm 1.3^{[2]}$ & $105.9 \pm 7.8^{[2]}$ & $65.5 \pm 5.0$ & $40.3 \pm 3.6[2]$ \\
\hline Judo [2] & 16 & $12.2 \pm 1.0^{[1]}$ & $97.5 \pm 7.1^{[1,3,4]}$ & $60.8 \pm 4.6^{[3,4]}$ & $36.7 \pm 3.2^{[1]}$ \\
\hline Middle- and long-distance running [3] & 19 & $13.1 \pm 1.2$ & $106.6 \pm 9.2^{[2]}$ & $67.8 \pm 6.7[2]$ & $38.8 \pm 3.7$ \\
\hline Modern pentathlon [4] & 14 & $13.0 \pm 0.8$ & $108.1 \pm 7.1[2]$ & $69.4 \pm 5.2[2]$ & $38.7 \pm 2.4$ \\
\hline Total number & 69 & & & & \\
\hline
\end{tabular}

tHb-mass - total hemoglobin mass. FFM - fat free mass. [1, 2, 3, 4, 5] Significant differences within male or female groups 
Table IV. Blood morphology indices (mean \pm SD)

\begin{tabular}{|lccccc|}
\hline Variable & $N$ & $\begin{array}{c}\mathrm{Hb} \\
{[\mathrm{g} / \mathrm{dl}]}\end{array}$ & $\begin{array}{c}\mathrm{Hct} \\
{[\%]}\end{array}$ & $\begin{array}{c}\text { RBC } \\
{[10 \% / \mathrm{ml}]}\end{array}$ & $\begin{array}{c}\text { Ret } \\
{[\%]}\end{array}$ \\
\hline Males & & & & & \\
\hline Cross-country skiing [1] & 20 & $15.5 \pm 0.7$ & $44.8 \pm 2.0$ & $5.16 \pm 0.28$ & $1.22 \pm 0.31$ \\
\hline Judo [2] & 34 & $15.2 \pm 0.7$ & $44.6 \pm 2.0$ & $5.22 \pm 0.32$ & $1.30 \pm 0.26[3]$ \\
\hline Middle- and long-distance running [3] & 21 & $15.5 \pm 0.6$ & $44.3 \pm 2.2$ & $5.23 \pm 0.20$ & $1.04 \pm 0.26[2]$ \\
\hline Modern pentathlon [4] & 24 & $15.0 \pm 0.6$ & $44.0 \pm 1.9$ & $5.03 \pm 0.24$ & $1.11 \pm 0.28$ \\
\hline Nordic combined [5] & 8 & $15.5 \pm 1.0$ & $44.1 \pm 2.8$ & $5.20 \pm 0.31$ & $1.07 \pm 0.27$ \\
\hline Total number & 107 & & & & \\
\hline Females & & & & & \\
\hline Cross-country skiing [1] & 20 & $14.1 \pm 0.7[4]$ & $41.8 \pm 1.8^{[3,4]}$ & $4.75 \pm 0.26$ & $1.12 \pm 0.26$ \\
\hline Judo [2] & 16 & $13.8 \pm 0.6$ & $41.3 \pm 1.7[4]$ & $4.77 \pm 0.23$ & $1.29 \pm 0.30$ \\
\hline Middle- and long-distance running [3] & 19 & $13.6 \pm 0.8$ & $40.0 \pm 2.4[1]$ & $4.64 \pm 0.31$ & $1.19 \pm 0.27$ \\
\hline Modern pentathlon [4] & 14 & $13.2 \pm 0.4[1]$ & $39.3 \pm 1.4[1,2]$ & $4.59 \pm 0.22$ & $1.19 \pm 0.37$ \\
\hline Total number & 69 & & & & \\
\hline
\end{tabular}

$\mathrm{Hb}$ - hemoglobin, Hct - hematocrit, RBC - red blood cells, Ret - reticulocytes. [1, 2, 3, 4, 5] Significant differences within male or female groups

Mean relative values of tHb-mass and volume parameters, normalized to fat-free mass, are presented in Table III. In endurance sports, tHb-mass/ kg FFM did not differ significantly in either women or men. However, significant differences in $\mathrm{tHb}$ mass/kg FFM were observed in judokas and crosscountry skiers, middle and long distance runners and pentathlon athletes among men and between judokas and cross-country skiers among women.

Mean values of BV, PV and RCV calculated per $\mathrm{kg}$ fat-free mass (similar to tHb-mass) did not differ in endurance sports or between judo and Nordic combined. In females mean values of above-mentioned indices did not differ within endurance sports. Blood volume differed significantly between the female judokas and the representatives of all three endurance sports, whereas PV differed between judo athletes and runners, as well as modern pentathlon athletes. Differences in RCV were found between judo and cross-country skiing.

\section{Blood morphology indices}

Mean values of haemoglobin concentration, haematocrit, red blood cell count and percentage of reticulocytes are presented in Table IV. Among the male athletes, regardless of the character of the sport, no significant differences in mean levels of $\mathrm{Hb}$, Hct and RBC were observed.

The judokas demonstrated significantly higher percentage of Ret compared to middle and long distance runners, whereas this parameter remained within the reference range.

Significant differences among the studied women were found in mean levels of Hct, both in endurance athletes (cross-country skiing/modern pentathlon and running/cross-country skiing) and between judo and modern pentathlon. Mean levels of $\mathrm{Hb}$ concentration in the studied group of females differed significantly only between two endurance sports. In female modern pentathlon athletes, the mean value of this index was significantly higher than in cross-country skiers.

\section{Discussion}

Our results confirm the earlier reports indicating higher relative $\mathrm{tHb}$-mass in endurance athletes compared to untrained subjects $[9,10]$, and nonendurance athletes $[10,25]$, although it seems surprising that the levels of this parameter are very similar in different endurance sports and relatively low among both male (12.8-13.1 g/kg BM) and female athletes (10.4-10.6 g/kg BM). This is even more surprising because in most sports (except middle and long distance running), studies were conducted among elite athletes, members of junior and senior national teams. A much higher tHb-mass (about $14 \mathrm{~g} / \mathrm{kg}$ BM) was observed in elite runners [26], highly trained cyclists, and elite crosscountry skiers [27], as well as in runners with national and/or international competitive experience [28]. Much higher levels were also observed in 23-year-old Swiss cross-country skiers and triathletes (14.2 g/kg BM), although the levels of $\mathrm{tHb}$ mass observed in 16-year-old representatives of the same sports were substantially lower (12.4 g/kg BM) [20], and in male elite German athletes (ranging from $13.3 \mathrm{~g} / \mathrm{kg} \mathrm{BM}$ in swimmers to $15.3 \mathrm{~g} / \mathrm{kg} \mathrm{BM}$ in professional cyclists [10], but in the latter study a non-conventional method was used). Lower values similar to our results were found by Schu- 
macher et al. [29] among German athletes representing various endurance sports (cycling, crosscountry skiing, long distance running and rowing) $(12.7 \pm 0.9 \mathrm{~g} / \mathrm{kg} \mathrm{BM})$ and Gore et al. [28] among Australian rowers $(12.6 \mathrm{~g} / \mathrm{kg} \mathrm{BM})$.

Comparison of the $\mathrm{tHb}$ mass levels obtained in this study is difficult in the case of female athletes because of the very low number of studies performed in women. The comparison is also problematic because of the inclusion of the women in one group with men [9] or collecting female athletes who represented different sports into one group [25]. Much higher levels of tHb mass (12.3 $\pm 0.9 \mathrm{~g} / \mathrm{kg} \mathrm{BM}$ ) compared to the athletes in this study (10.4-10.6 g/kg BM) were observed in Australian internationally competitive female road cyclists [21], although Gore et al. [28] observed substantially lower levels in female rowers (10.6-10.9 $\mathrm{g} / \mathrm{kg} \mathrm{BM}$ ), similar to those observed in the present study. Similar mean values of this parameter were also observed in elite female German hockey players, although it should be noted that this sport is not entirely of endurance character [11].

There is some evidence that $\mathrm{tHb}$-mass is related to FFM [29], but in only a few studies was tHbmass expressed per FFM, and those that exist have been conducted among male subjects [29, 30] or mixed groups [25]; hence the difficulty in comparing the results. In this study, in the three biggest male endurance sport groups, the value of this parameter ranged from 14.2 to $14.6 \mathrm{~g} / \mathrm{kg}$ FFM. Similar levels of tHb-mass/FFM (14.4 g/ $\mathrm{kg})$ were obtained by Schumacher et al. [29] in a group of 65 athletes who represented different endurance sports, whereas Steiner and Wehrlin [20] found, depending on the age of the subjects, the levels higher in a group of 21-year-old endurance athletes (15.2 g/kg FFM) and lower in a group of 16-year-old athletes (13.2 g/kg FFM).

Total haemoglobin mass in the male and female judokas in this study was 11.2 and $9.3 \mathrm{~g} / \mathrm{kg}$ BM and was at a substantially lower level compared to the representatives of all the endurance sports in our study. It should be emphasized that the levels of tHb-mass measured for this sport were similar to those observed typically in untrained subjects [19] and substantially lower than those found by Heinicke et al. [10] in Alpine skiers and in leisure sportsmen, and compared to those measured by Hinrichs et al. [11] in male and female hockey players, although the female and male judokas in our study represented a high international competitive level and the male group was additionally substantially older than the representatives of all endurance sports. Lower levels of tHb-mass in the elite judokas in the present study demonstrate that this index is not a prerequisite for achievement of high results in this sport, although some authors argue that higher aerobic power and capacity allow judo athletes to maintain a higher intensity throughout the match, delay accumulation of metabolites associated with the fatigue process and improve the recovery process between two consecutive matches [31]. Low levels of tHb-mass in judo, comparable to the untrained subjects [32], suggest that the contribution of exercise of endurance character is insufficient to stimulate the processes of increase in haemoglobin mass in blood, whereas the exercise of other character used in this sport does not affect this index.

Differences in $\mathrm{tHb}$-mass $\mathrm{kg} / \mathrm{BM}$ between the endurance and judo athletes were significant and were $12-14 \%$ in women and $14-17 \%$ in men, which is consistent with the differences observed in German athletes between downhill skiers and athletes from different endurance sports (7-25\%) [10]. A similar difference (15\%) between endurance and nonendurance athletes was also observed by Ulrich et al. [25] in 15-17-year-old athletes. When comparing tHb-mass calculated per fat-free mass, the differences observed between endurance and nonendurance athletes are substantially lower both in women (7-11\%) and in men (6-13\%), causing the significance of the differences between judo and some endurance sports (modern pentathlon and running in female and Nordic combined in males) to disappear. The same relationship has been emphasized by other authors [20, 25, 30, 31]. Furthermore, it should be noted that mean tHb-mass values calculated per fat-free body mass in endurance sport regardless of gender remain without significant differences. Among the studied male athletes, all the endurance sports were characterized by significantly higher BV calculated per kg body mass compared to judo, which was represented by significantly higher RCV and higher PV. This is consistent with the previous reports by others [10, 19, 25, 32], who demonstrated that endurance training affects in particular PV and consequently BV. However, the lack of longitudinal studies in this field does not allow for unequivocal determination of whether the significantly higher RCV and the resultant BV are a consequence of long-term exercise or genetic factors and the selection for endurance sports. It is worth emphasizing that the levels of BV, PV and RCV in males did not differ significantly in terms of the endurance sports analysed in this study (calculated both per total and fat-free body mass), although they remained at an average level, similar to tHb-mass. Much higher levels of the above volume indices were observed in German endurance athletes [10]. The BV, PV and $\mathrm{RCV}$ in endurance athletes in the present study ranged from 90.8 to $94.0,54.2$ to 56.4 and 36.6 to $38.0 \mathrm{ml} / \mathrm{kg} \mathrm{BM}$, respectively, whereas in the study by Heinicke et al. [10] these indices were higher 
than 100, 60 and $40 \mathrm{ml} / \mathrm{kg} \mathrm{BM}$, respectively, in 4 of 5 endurance sports. Similar higher values of the above volume indices in elite male athletes were also found by others [20]. It should be noted that the differences between one of the endurance sports (Nordic combined) and judo calculated per fat-free mass were insignificant for all the measured volume indices and $\mathrm{tHb}$-mass. This is likely to be caused by very low content of fat tissue in the group of Nordic combined athletes.

A similar relationship was observed among female athletes. All the three volume indices (BV, PV and RCV) calculated per total body mass differed significantly depending on the character of exercise (endurance or non-endurance), whereas additional significant differences in plasma volume were observed between cross-country skiing and modern pentathlon. Lower PV in cross-country skiers, without significant differences in BV, points to higher RCV levels in this group, which is confirmed by the highest value of RCV/FFM in this group (the only sport where this index was higher than in judo). This is also reflected by the highest mean $\mathrm{tHb}$-mass/FFM (also the only group which differed in these terms from judo). In other endurance sports (middle and long distance runners and modern pentathlon) the BV was largely determined by the PV (the levels of PV/FFM higher than in judo). These results demonstrated that $\mathrm{tHb}$-mass and volume indices normalized to FFM might provide additional information concerning the differences in terms of individual sports, which is not indicated when expressing these indices per body mass only.

A meta-analysis carried out by Schmidt and Prommer [19] among 490 athletes living at sea level, concerning the relationships between $\mathrm{VO}_{2}$ max and BM-related tHb-mass and BV, PV and RCV, demonstrated that mean values of $\mathrm{tHb}$-mass found in this study in endurance sports (both in women and men) correspond to the levels found in high performance athletes. Furthermore, BV, PV and RCV levels correspond to the athletes characterized by the level between moderate and high performance, although the vast majority of female and male athletes demonstrated a high level of fitness (they were members of the national senior and junior teams). Lower values of the above-mentioned indices are likely to be caused by the low age of the subjects: nearly $60 \%$ of the studied athletes were under 20 years of age.

Mean values of volume parameters observed in judo, normalized to body mass, are (similar to tHbmass) significantly lower compared to endurance disciplines. However, it is remarkable that BV was slightly higher than the levels observed in untrained persons [7, 10, 19]. The levels of PV and RCV in judokas are also higher than mean values observed in untrained subjects; however, both indices are in the upper ranges of the normal values observed in people who are not training [32].

The differences in the values of the above volume indices, expressed per kg body mass between the athletes from endurance and non-endurance sports (judo), are similar in females and males and are (depending on the sport) $11-17 \%$ for BV, $10-20 \%$ for PV and $11-15 \%$ for RCV, and in the case of the two first indices are similar to the differences observed by Heinicke et al. [10]. In studies by these authors, the differences between downhill skiers and athletes from different endurance sports were $11-22 \%$ for BV and $12-19 \%$ for PV, whereas the differences in RCV ranged from $12 \%$ to $29 \%$ and in most of the endurance sports (apart from swimmers) they exceeded the upper level (15\%) observed in the present study.

Despite the significant differences in tHb-mass between the sports with different character of exercise, its concentration remained at similar levels. The only significant differences in $\mathrm{Hb}$ concentration observed in the present study were found in female athletes from two endurance sports. The lack of significance of differences in blood morphology indices between sports of different character of the exercise, with simultaneously significant differences in tHb-mass and significant differences in the abovementioned morphological indices in female athletes from some endurance sports, and the lack of significant differences in tHb-mass, confirm the previous reports which demonstrated that indices dependent on dilution, such as Hb, RBC and Hct, are not good parameters to provide an indirect measure of haemoglobin in blood in athletes.

The results of our study, both in male and female athletes, point out the lack of differentiation in relative values of $\mathrm{tHb}$-mass, BV, PV, and $\mathrm{RCV}$ in endurance sports, and significant differences between the values of these indices among disciplines of different type. However, in our study athletes from only one non-endurance discipline participated, which is a limitation of this study. The obtained results do not allow us to explain why the above-mentioned differences exist, but only suggest that the type of the exercise might affect the level of these indices, although genetic determinants cannot be excluded. Longitudinal studies are needed to explain the above listed concerns.

Measurements of tHb-mass and BV parameters showed that in athletes (particularly in endurance sports) haemoglobin concentration and other morphological indices dependent on PV have limited diagnostic value in terms of the evaluation of haematological status.

\section{Acknowledgments}

We would like to express our huge gratitude to Dr. Nicole Prommer and Prof. Walter Schmidt for 
her help in reaching proficiency in tHb-mass measurement.

The study was financially supported by the Ministry of Science and Higher Education (grant no. N N404 5252 38).

\section{References}

1. Saltin B, Strange S. Maximal oxygen uptake: "old" and "new" arguments for cardiovascular limitation. Med Sci Sports Exerc 1992; 24: 30-7.

2. Śliwowski R, Rychlewski T, Laurentowska M, et al. Changes in aerobic performance in young football players in an annual training cycle. Biol Sport 2011; 28: 55-62.

3. Martino M, Gledhill N, Jamnik V. High VO2max with no history of training is primarily due to high blood volume. Med Sci Sports Exerc 2002; 34: 966-71.

4. Kanstrup IL, Ekblom B. Blood volume and hemoglobin concentrations as determinants of maximal aerobic power. Med Sci Sports Exerc 1984; 16: 256-62.

5. Green HJ, Carter S, Grant S, Tupling R, Coates G, Ali M. Vascular volume and hematology in male and female runners and cyclists. Eur J Appl Physiol Occup Physiol 1999; 79: 244-50.

6. Schmidt W, Prommer N. Impact of alterations in total hemoglobin mass on VO2max. Exerc Sport Sci Rev 2010; 38: 68-75.

7. Eastwood A, Bourdon PC, Norton KJ, Lewis NR, Snowden $K R$, Gore CJ. No change in hemoglobin mass over 40 days of physical activity in previously untrained adults. Scand J Med Sci Sports 2012; 22: 722-8.

8. Ahlgrim C, Pottgiesser T, Kron J, Duerr H, Baumstark M, Schumacher YO. Relations between haemoglobin mass, cardiac dimensions and aerobic capacity in endurance trained cyclists. J Sports Med Phys Fitness 2009; 49: 364-71.

9. Eastwood A, Bourdon PC, Withers RT, Gore CJ. Longitudinal changes in haemoglobin mass and VO2max in adolescents. Eur J Appl Physiol 2009; 105: 715-21.

10. Heinicke K, Wolfahrt B, Winchenbach P, et al. Blood volume and hemoglobin mass in elite athletes of different disciplines. Int J Sports Med 2001; 22: 504-12.

11. Hinrichs T, Franke J, Voss S, Bloch W, Schänzer W, Platen P. Total hemoglobin mass, iron status, and endurance capacity in elite field hockey players. J Strength Cond Res 2010; 24: 629-38.

12. Brun JF, Bouchahda C, Chaze D, Benhaddad AA, Micallef JP, Mercier J. The paradox of hematocrit in exercise physiology: which is the "normal" range from an hemorheologist's viewpoint? Clin Hemorh Microcirc 2000; 22: 287-303.

13. Li Y, Zhu Y, Zhang J, Zhang X, Zeng Y. Biochemical change and endocrine responses in pre-competition training in elite swimmers. Biol Sport 2012; 29: 71-5.

14. Prommer N, Sottas PE, Schoch C, Schumacher YO, Schmidt $W$. Total hemoglobin mass - a new parameter to detect blood doping? Med Sci Sports Exerc 2008; 40: 2112-8.

15. Silva ASR, Santhiago V, Popoti M, Gobatto CA. Hematological parameters and anaerobic threshold in Brazilian soccer players throughout a training program. Int J Lab Hemat 2008; 30: 18-166.

16. Siewierski M, Słomiński P, Białecki R, Adamczyk J. Athletic performance of swimmers after altitude training $(2,300$ $m$ above sea level) in view of their blood morphology changes. Biol Sport 2012; 29: 115-20.
17. Ozen SV. Reproductive hormones and cortisol responses to plyometric training in males. Biol Sport 2012; 29: 193-7.

18. Mejuto G, Arratibel I, Cámara J, Puente A, Iturriaga G, Calleja-González J. The effect of a 6-week individual anaerobic threshold based programme in a traditional rowing crew. Biol Sport 2012; 29: 297-301.

19. Schmidt W, Prommer N. Effects of various training modalities on blood volume. Scand J Med Sci Sports 2008; 18 (suppl 1): 57-69.

20. Steiner T, Wehrlin JP. Does hemoglobin mass increase from 16-21 and 28 in elite endurance athletes? Med Sci Sports Exerc 2011; 43: 1735-43.

21. Garvican LA, Martin DT, McDonald W, Gore CJ. Seasonal variation of haemoglobin mass in internationally competitive female road cyclists. Eur J Appl Physiol 2010; 109: 221-31.

22. Durnin JVGA, Womersley J. Body fat assessed from total body density and its estimation from skinfold thickness: measurements on 481 men and women aged from 16 to 72 years. Br J Nutr 1974; 37: 77-97.

23. Schmidt W, Prommer N. The optimised CO-rebreathing method: a new tool to determine total haemoglobin mass routinely. Eur J Appl Physiol 2005; 95: 486-95.

24. Prommer N, Schmidt W. Loss of CO from the intravascular bed and its impact on the optimised CO-rebreathing method. Eur J Appl Physiol 2007; 100: 383-91.

25. Ulrich G, Bärtsch P, Friedmann-Bette B. Total haemoglobin mass and red cell profle in endurance-trained and nonendurance-trained adolescent athletes. Eur J Appl Physiol 2011; 111: 2855-64.

26. Prommer N, Toma S, Quecke L, et al. Total hemoglobin mass and blood volume of elite kenyan runners. Med Sci Sports Exerc 2011; 42: 791-9.

27. Jelkmann W, Lundby C. Blood doping and its detection. Blood 2011; 118: 2395-404.

28. Gore CJ, Hahn AG, Burge CM, Telford RD. VO2max and haemoglobin mass of trained athletes during high intensity training. Int J Sports Med 1997; 18: 477-82.

29. Schumacher YO, Ahlgrim C, Pottgiesser T. Evaluation of anthropometrical reference parameters for hemoglobin mass in endurance athletes. J Sports Med Phys Fitness 2008; 48: 509-14

30. Prommer N, Mutke S, Schmidt W. Lean body mass is closely related to total hemoglobin mass but less to VO2max. Med Sci Sports Exerc 2006; 38: 955.

31. Franchini E, Del Vecchio FB, Matsushigue KA, Artioli GG. Physiological profiles of elite judo athletes. Sports Med 2011; 41: 147-66.

32. Sawka MN, Convertino VA, Eichner ER, Schnieder SM, Young AJ. Blood volume: importance and adaptations to exercise training, environmental stresses, and trauma/ sickness. Med Sci Sports Exerc 2000; 32: 322-48. 